\section{Solidarity and the study of migrants and refugees}

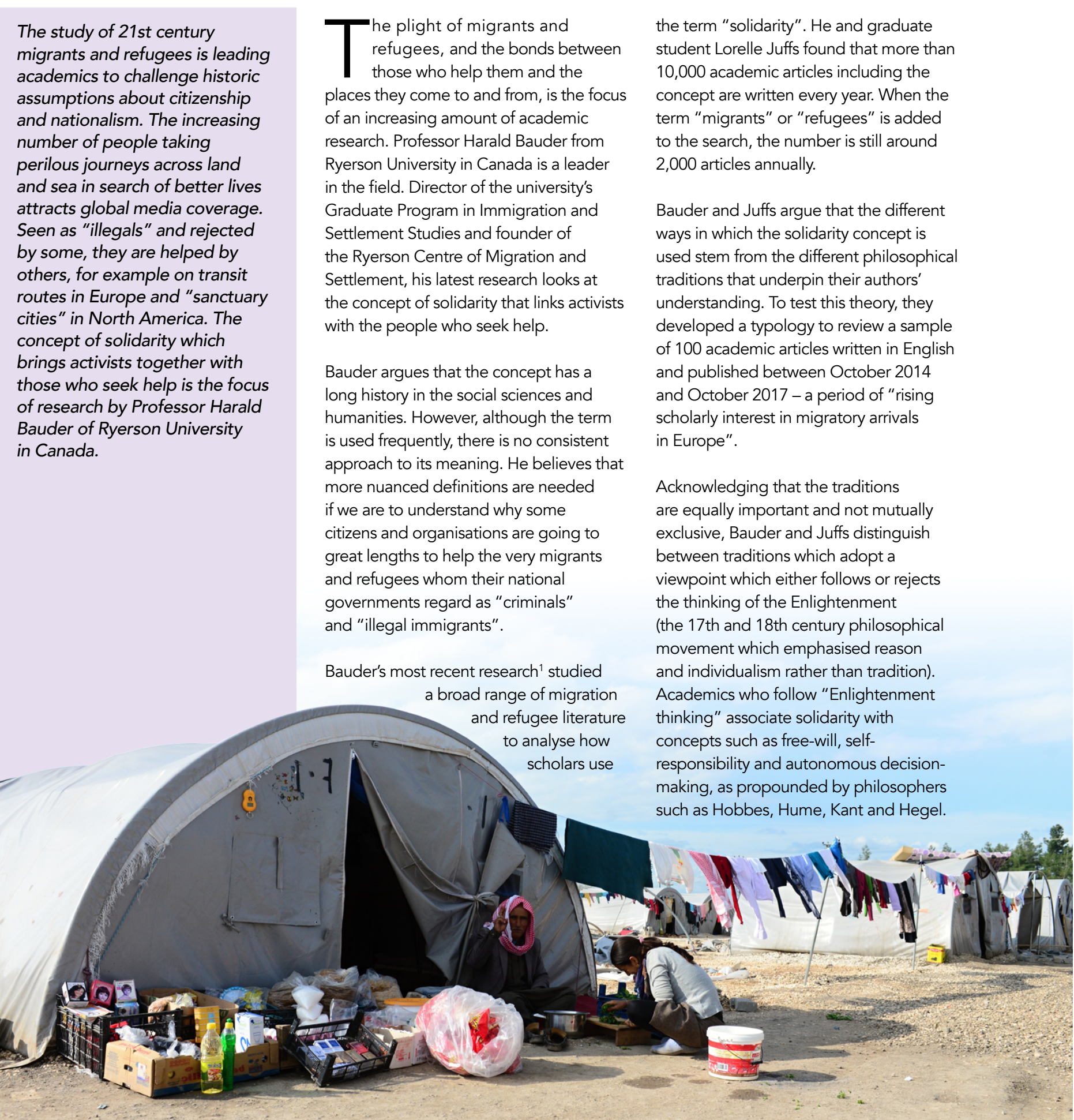

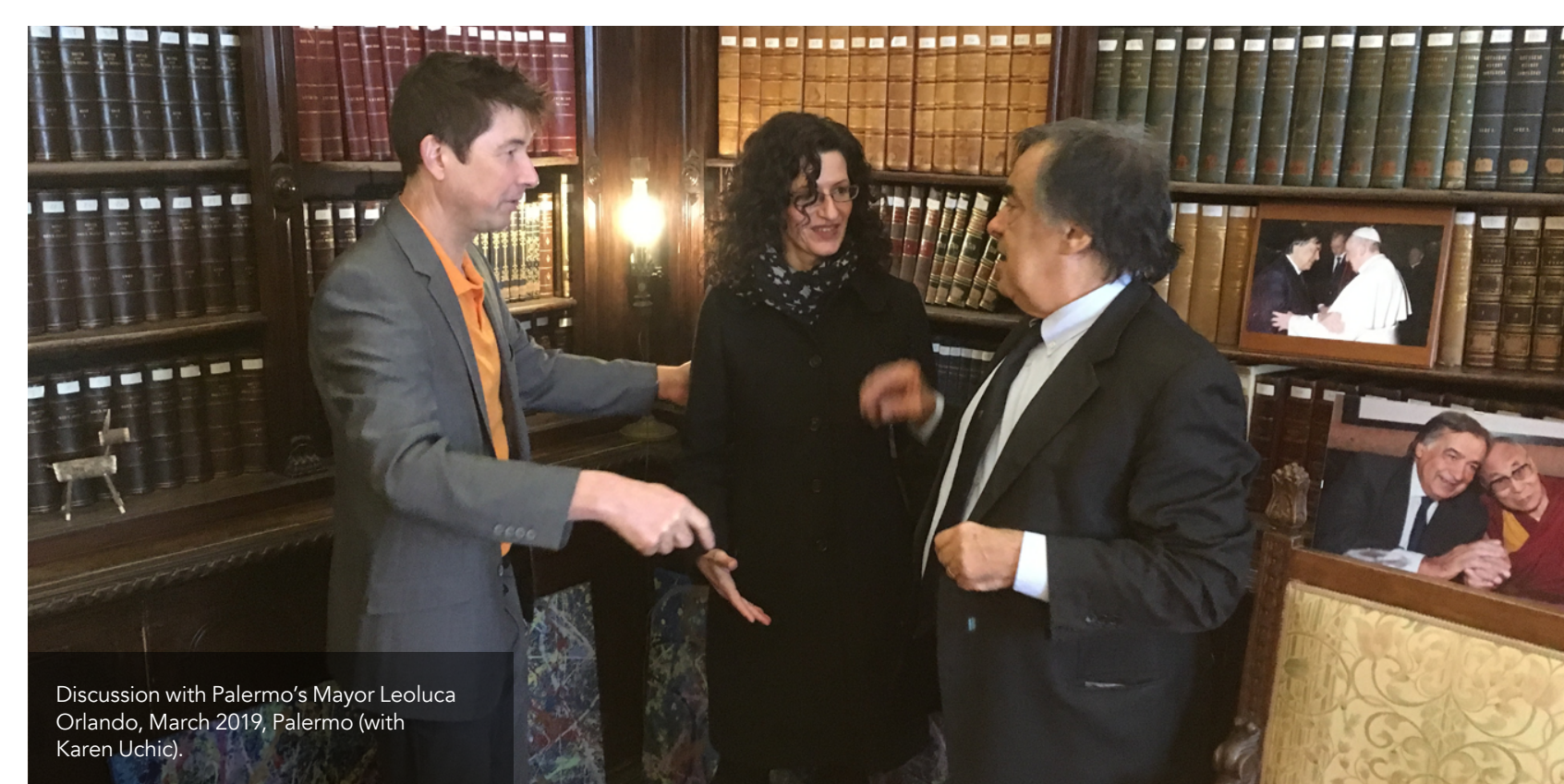

However, other scholars either Enlightenment tradition" which is either derived from ideas about loyalty to a social group based on origin and belonging, or takes the view that solidarity derives from people having Indigenous world views "grounded in common historical, social and/or political experiences or memories". Bauder and Juffs found no single use of the concept of solidarity in the articles sampled, but rather a degree of overlap and an inconsistent approach to the term's use. The research also discovered that con Enlightenment

than non-Enlightennnd more often that more than half the articlitions, and interpreted "solidarity" in ways that could be traced to the work of Kant or Hegel. For example, articles based on Kant's rationalisation took the view that solidarity is "an expression of a 'community of us all, governed by universal rational and moral principles", while those which followed a Hegelian perspective saw individuals as being "socially mbedded" and connected to others expression of reciprocity"

As a result of their analysis of the literature, Bauder and Juffs urge writers and academics to use the concept of soling "close and explicit attentistently the particular social and political practices and the philosophical and conceptual underpinnings they associate with the concept". They concluded: "We are not advocating for developing a single definition or application of the concept of solidarity. Rather, that the value of outlining the different types of solidarity occurring

since the 17th century when the Treaty of Westphalia brought an end to the Thirty Years War (the war between Catholics and Protestants that led to the break-up of an Empire and the creation of the modern European states.

Following the work of Torpey4, Bauder argues: "International migrants and refugees destabilise the 'Westphalian' political order that has divided the earth's surface into territorial states,

The concept of solidarity is helping us into citizens and to better understand why individuals and organisations from around the world are coming together in response political potential the plight of migrants and refugees. in demonstrating the variability and often contradictory uses of the concept." GEOGRAPHY AND SOLIDARITY Bauder's research into the concept of solidarity builds on additional work which explores solidarity's geographical dimensions and the links between places migrants come to and from. The themes are explored in a book Bauder co-edited with Jonathan Darling, published earlier this year', and Bauder's companion papers on the politics of place. ${ }^{3}$ This research places solidarity in the wider context of globalisation and refugees requires a geographical perspective. When people migrate or flee war or other circumstances, they connect places, and their arrival causes people in different circumstances to interact with each other."

Those interactions are often in stark relief to the prevaling political culture. For example, Bauder cites the "sanctuary cities" movement where some municipa authorities, notably in Europe, Canada and the United States, have taken a more heral approach to migrants and refugess than their national governments. Not only have these municipal authorit 


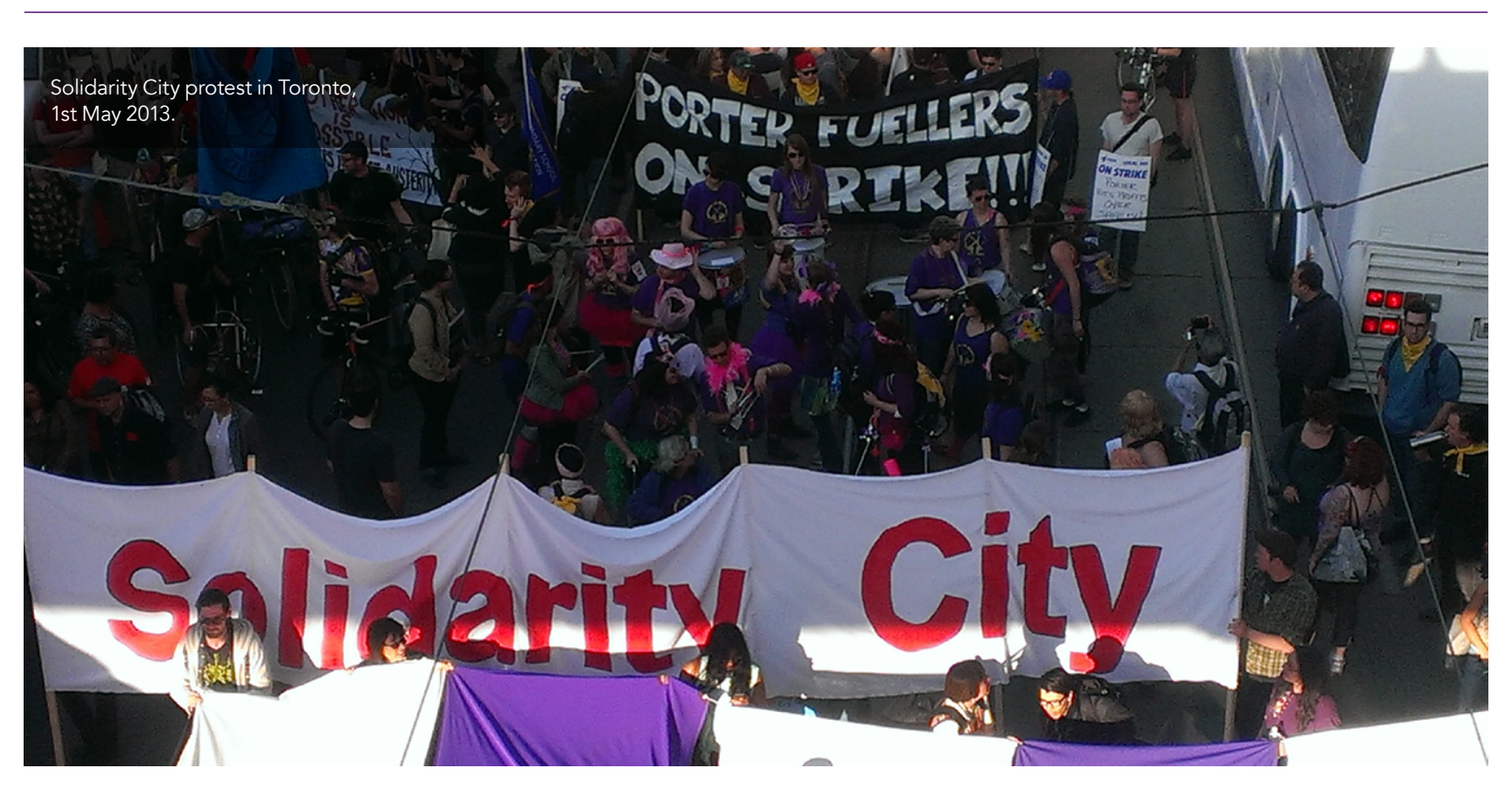

policies, they have also provided access senvices for migrants and refugees.

The world's attention has recently been particularly drawn to the plight of migrants and refugees who attempt to cross the Mediterranean Sea, with often tragic consequences. Palerm in Sicily provides a good example of how different approaches to the people who arrive on Italy's shores challenge historic assumptions about citizenship and nationalism.

In 2015 the city's Mayor Leoluca Orlando issued the "Charter of Palermo "which human right and calls for the abolition of residence permits and a fundam reorientation of European refugee and migration policies.

In an interview with Bauders, Orlando said: "We cannot say today that Palermo respects the rights of migrants. Because we have no migrants in Palermo. If you ask how many migrants are in Palermo, then I do not answer 100,000 or 120,000 , but none. If you are in Palermo, you are a Palermitan.
Bauder is prompting us to see solidarity as a transformative process, beyond the reach of sovereign states, which is forcing us to rethink the concept of national identity in the 21st century.

Orlando argues that the global refugee is shifting and this response is largely of modern times: security, climate change, Cities and municipal authorities and peace. He told Bauder: "Only are taking initiatives in opposition to migrants experience these three topics at national governments which demonise the same time. They have a problem with migrants and refugees as "criminals" security - they have no security. Climate and "ilegal immigrants" who can be nate change, or the people of Noway the firstiction country? Peace - and tor... migrin are the victims of war, not us! Today, the three different themes are united

SOLIDARITY AS TRANSFORMATION The concept of solidarity is helping us to better understand why individuals and organisations from around the world are coming together in response to the plight of migrants and refugees. The powerbase crisis brings together three major themes driven by activists at the local level. (a)

\section{Behind the Research}

\section{Dr Harald Bauder}

E: hauder@ryerson.ca T: +1 416-979-5000 x7193 W: https://www.ryerson.ca/hbauder/

\section{Research Objectives}

Professor Bauder's research explores migration, immigration and social policy.

\section{Detail}

$\begin{array}{ll}\text { Dept. of Geography and Environmental } & \text { the } 2015 \text { Konrad Adenauer Research } \\ \text { Studies, Ryerson University, } 350 \text { Victoria } & \text { Award from the Alexander von }\end{array}$ Studies, Ryerson University, 350 Victoria St. Toronto ON M5B 2K3

Bio Director, Graduate Program in Immigration and Settlement Studies of the Ryerson Centre of Migration and Settlement (RCIS): recipient of Humboldt Foundation in collaboration with the Royal Society of Canada; recent monograph: Migration Borders

Funding

Social Sciences and Humanities Researc Council of Canada (SSHRC) Freiburg European Union's Horizon 2020 research and innovation programme under the Marie Skłodowska-Curie grant.

Collaborators Jonathan Darling, co-editor of "Sanctuary Migration Citizenship and Rights" Manchester University Press.

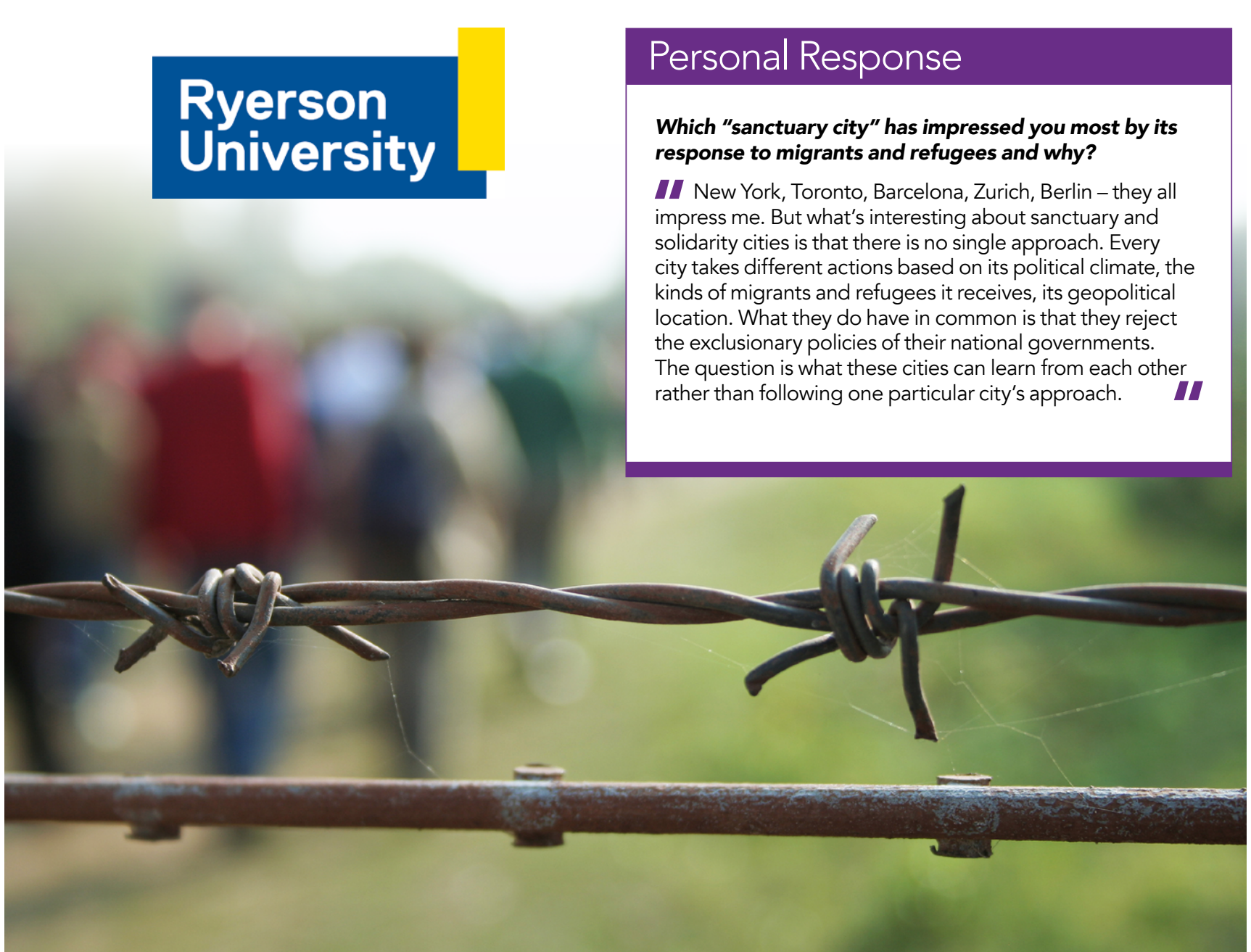

